Performance Research

A Journal of the Performing Arts

\title{
Growing Together
}

\section{Shin Eun Kyoung}

To cite this article: Shin Eun Kyoung (2016) Growing Together, Performance Research, 21:6, 98-102, DOI: $10.1080 / 13528165.2016 .1239905$

To link to this article: http://dx.doi.org/10.1080/13528165.2016.1239905

\section{曲 Published online: 01 Dec 2016.}

Submit your article to this journal

Q View related articles ¿

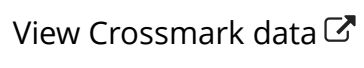




\title{
Growing Together Emancipatory lessons from North Korean defectors' art education in South Korea
}

\author{
SHIN EUN KYOUNG
}

${ }^{1}$ The Korean word Juche is usually translated as 'self-reliance'. Juche, a compound of $J u$ (owner, subject) and Che (body) in hanja (Chinese characters), literally translates as 'the owner of the body'. Kim Jong-il wrote that 'the basic advantage of our form of socialism (Juche) is that it is a man-centred society, a society which considers everything with man at the centre and makes everything serve him' (Kim 1990:6). In 1955 Kim Il-sung 'stressed the need to domesticate or "Koreanize" communism', i.e. 'the foundation of self-determinant action' (Lee 1981:29). 'North Korea's Juche is best understood as the institution that has emerged out of the interactions between Kim Il -sung's group and its challengers and between the North Koreans and outsiders, particularly the Soviets and Chinese' (Suh 2013:24).
In order to address some of the fundamental queries concerning the meaning of art in our time, and the necessity of art education, I would like to look into an alternative school for North Korean youth defectors in South Korea. Matters of art pre-education are not only an obstacle for North Korean youth defectors, but also a problem that potentially affects the art education of our time. People who provide education could easily deal with learners as they intend. North Korean life is dominated by the Kim family's ideology; people there have a distorted view of art, which makes them praise the North Korean system and intensify the ideology. However, after entering to South Korea, defectors experience art in a different way and their art education is similar to art therapy to remove their pre-education concerning art. That is to say, an education can also give liberty to the oppressed person. Thus, I would like to introduce one example of emancipatory art education through looking at the North Korean youth's art re-education in South Korea.

\section{ART AND IDEOLOGY}

'Juche ideology' (self-reliance ideology) is deeply engrained in the education of North Korean youth, despite their having been challenged by experiences of famine and food shortages. ${ }^{1}$ Juche ideology is the single fundamental pillar of their entire educational upbringing. North Korea's art is also intended to guide the people towards the single thought and ideology of the Juche idea. Kim Jong-il, a second-generation dictator, was his father Kim Il-sung's minister of culture. Early in his ministerial role, he emphasized the development of art and culture in a distinctly
North Korean style and tried to enhance the 'cultural and technical sophistication' (Kim 1990a [1982]: 38) of the people with the purpose of promoting 'Juche ideology'. In particular, he created an authoritative genre of art as 'the anti-Japanese revolutionary arts'. The genre deals with the model of anti-Japanese revolutionary fighters because Kim thought that such works of art could provide viewers with the opportunity to re-experience 'what the revolutionaries in those days experienced' (Kim 1988:7,8). This genre of arts is widely promoted and taught by the government. Due to the "brain washing' tendency and peculiarity of North Korean art, well-educated North Korean defectors are often quite confused by the differences of arts when they are re-educated in South Korea.

\section{EDUCATION OF DEFECTORS}

Close to 30,000 North Koreans have resettled in South Korea. In the region of 20 per cent of them are school-aged children (Han et al. 2009:3) who are suitable for normal schooling in South Korea. The problem is that due to the difficulty of adapting to life in South Korea, their attendance rate is as low as 57 per cent according to a report from Ministry of Education, Science and Technology (MEST)(Han et al. 2009:46).

North Korea youth defectors in the early stage of entering South Korea often are characterized by poor growth from having experienced food shortages, underachievement of standard academic levels due to a lack of proper education time, psychological disorders of varying degrees and culture shock from the 
differences between North and South Korea. Moreover, if they had left family members behind in North Korea, the North Korean youth felt more fear and uneasiness because their family would surely be in danger when the facts become known to the state political security department in North Korea. Additionally, there is much bias towards North Korean defectors and the bias is a widely prevalent view in schools and society (Kim 2004:90-91). Most of them have "psychological health issues such as post-traumatic stress disorder (PTSD)' (Go 2014: 1). However, the level of PTSD can differ according to where and how they were educated, and whether they received therapy after settling in South Korea. Many guidance counsellors have witnessed that often when North Korean youths get enough time for art activity, they overcome their disorders or trauma (Jang 2007:10).

Research studies have reported youth defectors' poor adjustment as causing difficulty in studying and subsequently having dire effects on their education. An increased awareness of the special needs of youth defectors has effected change in the environments of their education. For example, teachers are widely informed through handbooks and mentoring casebooks published on the subject. Fine art, theatre, and music therapy for North Koreans have been developed for integration into the curriculum, and are still being further developed.

Consequently, youth defectors are given more opportunities to attend alternative schools and after-school programmes where they are provided with individual tutoring. Regarding the underachievement of standard academic levels of North Korean youth, alternative schools and study rooms provide students with the opportunity to take mainstream classes (maths, science, social science, English, world history and Korean language) for school qualification examinations and college entrance exams. Art is not a major subject in school, but it is treated as an important subject for the development of students' social adaptability and psychological therapy. Since 2004, the South Korean government has established more than thirty different types of alternative schools and group

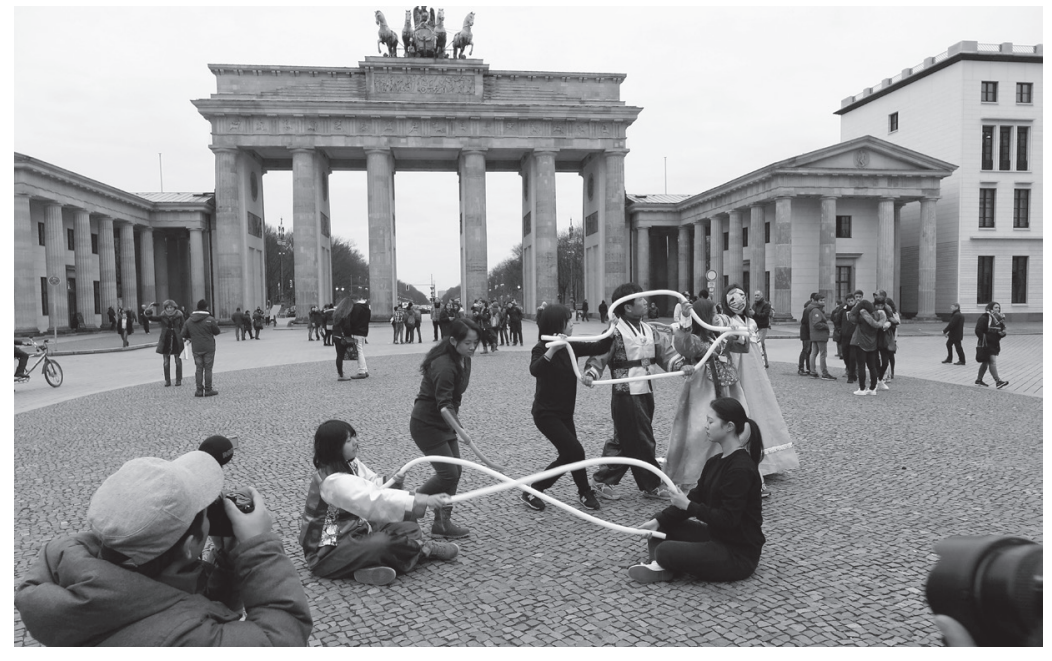

home studying organizations across the country to help young defectors to adapt more easily to life in Korea, and since then attendance has gradually improved. The drop-out rate has decreased from 10.8 per cent in 2008 to 2.5 per cent by 2014 (Kim et al. 2015:6).

\section{THE THEATRE GROUP SETNET}

From 22 November to 5 December 2015, the theatre group Setnet was invited to Dresden and Berlin, Germany by the government agencies (including the Saxony State Chancellery) as part of the celebration of the twenty-fifth anniversary of German reunification. Setnet presented a seventy-minute, non-verbal performance consisting of pantomime, puppet play, music concert, group dance, photo, video and shadow show called Vor dem Stacheldraht ... Duett für eine Stimme (Before Barbed Wire ... Duet for One Voice). Photographs and video material showed the history of division and fratricidal tragedy during the Korean War. The short film piece was based on the true story of a youth defector's resettlement in Seoul. Such materials helped the audience understand Korean history and North Korean defectors' recent lives in South Korea. Union, recovery, peaceful coexistence and renewal were the main themes of the work (Koreaverband 2015).

Setnet Theatre consists of North Korean students at the Setnet Alternative School in South Korea. Setnet School started in 2001
Performance in front of Berlin's Brandenburg Gate, 2 December 2015. Photo by Setnet school 
'Vor dem Stacheldraht ... Duett für eine Stimme' Performance at Werkstatt der Kulturen, Berlin, 4 December 2015.

Photo by Setnet school as simply a weekend school to help children adjust to Korean culture. It was expanded as an alternative cultural school for North Korean youth in 2004 (Setnet 2010) and now specializes in art activities such as theatre and performance. Setnet has an educational philosophy that differs from other typical schools in South Korea, and academic subjects are split into five themes:

1. Fundamental subjects for settlement in South Korea Society (Language, English, Math, Society, Science, History, Korean Culture, and Religion)

2. Consultation and art activity subjects for the formation of a positive mind (Elective art activity courses: Music, Fine Art, Dance, Folklore, Theatre Play; Guidance counselling sessions for developing studies)

3. Democratic culture community exercise subjects (Daily Life Writing and Reading, Capitalism Economy Reading, Love and Marriage, Media and Video Production, Contemporary History, Economy of Daily Life, International Culture, Korean Culture and Religion, Communication and Debate, Pop culture reading, Law and Common Sense)

4. Creating a whole community body ([group] music, group theatre activity, cultural exchange with South Koreans of the same age)

5. Field-based Experiential Learning (Climbing, Agriculture, Social service activities, Historical/ cultural inquiry)

(Setnet 2010)

With the inclusion of these five themes, Setnet School already sets itself apart from regular schools. Unlike many South Korean schools that focus on fundamental subjects, Setnet prioritizes group work and creative activities. In particular, in every semester

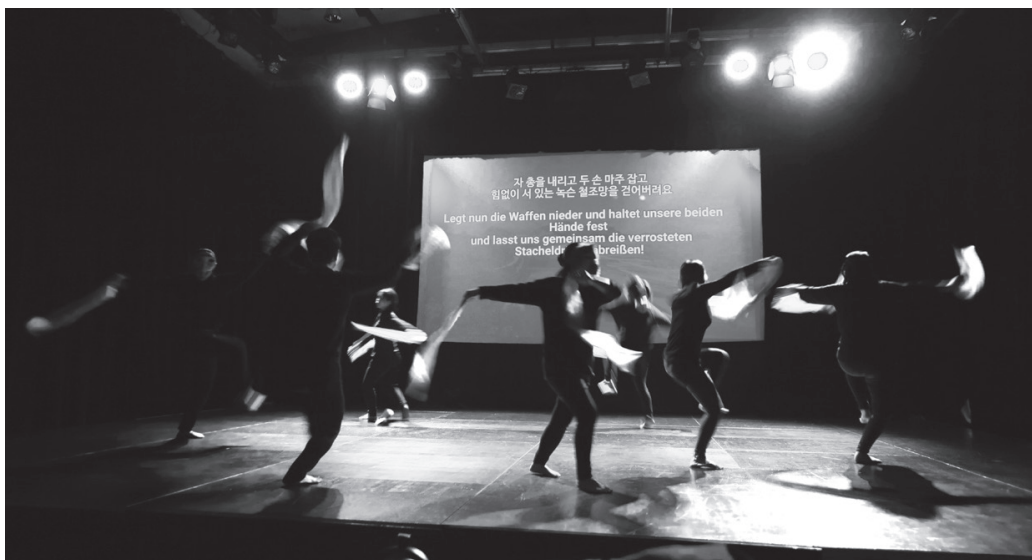

students have an opportunity to perform on stage. On the homepage of the Setnet School website, principal Park Sang-young explains the reason for emphasis on art activity:

The most important goal of Setnet education is communication. We should learn the various skills for communication, such as peaceful communication between body and mind, equal communication between I and other, warm communication between I and thing, and flexible communication between I and world. These skills cannot be learned only in the classroom; instead, we should go out and test them and let them fill our own lives.... We aim to provide our students with various cultural and art activities because they should develop a healthy relationship with themselves and get a flexible and effective communication capability. (Park 2016)

Park recognized the students' hardest problem as communication and thus added focus on culture and arts to foster communication skills. Through theatre activities North Korean youth have a forum to practice communication.

\section{A UTOBIOGRAPHICAL THEATRE}

Most Setnet and other alternative schools for defectors create theatre pieces with autobiographical motifs. The autobiographical theatre is based on personal storytelling in which the life stories of the individual participants are collected and rearranged; the resulting story can be a mixture of fictional and real backgrounds. Participants then re-enact their self-reflective roles on stage. The use of 'storytelling, enactment and the embodiment of roles' seemed like representative method in 'dramatherapy' (Mackenzie 2013:131). The theatre piece Vor dem Stacheldraht ... Duett für eine Stimme is comprised of Setnet students' autobiographical stories based on their experiences while escaping from the North and resettling in South Korea. While participating in such theatre, students tend to expose their hidden distress and trauma through the exercise that helps them regain selfesteem and frees them from being entrenched in negative memories (Kim et al. 2016b: 58).

Jang Hong-sun applies an 'autobiographical theatre' form to theatre practice with North 
Korean youth in order to suggest an 'effective theatre therapy model' for North Koreans (Jang 2007:3). A research study was conducted with five or six Setnet students over ten class sessions in a three-month training programme. This programme was designed with two parts: autobiographical theatre practice, and body exercises for theatre practice. The body exercises were based on six activities (12): 'body training' based on Jerzy Grotowski’s 'physical method' (13); 'trust and concentration'; 'improvisation' (14); Konstantin Stanislavsky’s 'emotional memory' (15); 'role-playing'; and the 'understanding of autobiographical theatre'. Then, the autobiographical theatre was designed through 'the students' selfreflective view of their past, present, and future' (114). During self-reflective processes, they were 'faced with uncomfortable sentiments and emotions' (115); the participants were distressed, but nevertheless expressed the often difficult, highly personal and complex subject matter. The students' autobiographical portrayals in performances enabled them to 'practice being their changed selves and to form bonds with others through acting [these roles] publicly, which became opportunities for change' (115). In his research, Jang testified:

Through the autobiographical performance practices, the youths gained the ability to more clearly recognize their sentiments and desires, and received the strength to recognize their self-roles and the capacity to positively lead relationships. These effects stemmed from theatre's ability to transform the participants into independent beings in their own lives. (Jang 2007:115; my emphasis)

The defectors experienced emancipation of their bodies, as well as mind and content, through art activities in South Korea. Intense bodily activity brought them emancipation of their bodies because the 'body activities' purpose is to release their body (Jang 2007:13) not to discipline and train the body for particular expression. The performers should release their bodies first because bodily release is linked with emotional and psychological release. After bodily release, emotional awareness is awakened and it becomes possible to express new ways of unconstrained body expression. In autobiographical theatre, performers deviate from their psychological oppression and can confront it; through this process, they can emancipate themselves from mental depression. On stage, they do not conceal what they are experiencing, and they cry and laugh together with the audience. They are comforted by the emotional support given by their audience or other participants. Moreover, the creation of the group is not formed by a particular ideology. Each individual student can stand firmly in the centre and tell his or her own autobiographical story independent from ideological content. Such experiences of emancipatory theatre are comparable to Augusto Boal's The Theatre of the Oppressed. Moreover, focusing on Brechtian epic theatre techniques and their educational effect on students, the North Korean youth theatre can also be linked with Bertolt Brecht's Lehrstück (learning-play). Setnet theatre students learned about the value of reunification through the practice of theatre, and after the performance in conversation with the audience, the actors spoke more directly about the value of Korean reunification. Boal and Brecht's theatre have educational and ethical purposes for both actors and audiences, and regarding their possibilities of learning through acting, playing roles and attitudes, there is no boundary between actors and audiences. In contrast, the North Korea youths' autobiographical theatre tends more toward theatre therapy because it is much more focused on the emancipation of the actor than on the audience.

\section{CONCLUSION}

We should take a broader perspective on the relation between art education and society. Art is a reflection of the society in which it is produced. Through art education, students learn what kinds of art product could be accepted by the audience of a particular society. Thus, art education governs the production of art according to what is needed in a society. In North Korean art, the motivation is certainly 
apparent. In the same vein as the broader North Korean society, the art is concentrated on the propaganda of the government's ideology. On the other hand, through the expansion of the capitalist production system, South Korean art becomes commodified and art production becomes increasingly dictated by the marketability of a particular art form. Under increasingly competitive circumstances, the art market is propelled by consumerism, which affects even art education. For example, currently musical departments are burgeoning at universities in South Korea because musical theatre continues to gain a market share in the performing art market of Korea. In our time, art education is being shaped by art market forces. Therefore, the educational environment has turned into an art factory due to a focus on developing arts that stimulate consumers and induce them to buy it or consume it.

Such a perspective on art education may seem somewhat sceptical, but it stands in stark contrast to the art education that is being taught in the alternative schools, which does not depend on the consumer. Art education in alternative schools such as Setnet is centred on production and process, rather than on creating a marketable commodity. Thus, it makes for a form of art experience that is shared with the audience and creates a forum for communication and education. In the process, those who were previously educated in North Korea become capable of creating emancipatory art. When art education allows for the individual to flourish, the individual can become capable of creating powerful art to stimulate a healing process for the agony and isolation that has been endured. Such an art education that focuses on the emancipation of the individual and gives space to grow and heal is an art education worth our time.

\section{REFERENCES}

Go Myong-Hyun (2014) 'Resettling in South Korea: Challenges for young North Korea refugees', Issue Brief, Seoul: The Asian Institute for Policy Studies.

Han Man-gil, Yoon Jong-hyuk, Lee Hyang-gyu, Kim Ilhyuk and Lee Gwan-hyung (2009) A Study on the Current Education of North Korean Youth Defectors and the Support Plan, Seoul: Korean Educational Development Institute.
Jang Hong-sun (2007) A Case Study on North Korean Youth Defectors through Autobiographical Performance Practices, Seoul: Kookmin University (dissertation).

Kim, Jong Il (1988) On Establishing the Juche Outlook on the Revolution: Talk to the senior officials of the central committee of the worker's party of Korea, 10 October 1987, Pyongyang: Foreign Language Publishing House.

Kim, Jong Il (1990a) On the Juche Idea: Treatise sent to the national seminar on the juche idea held to mark the 70th birthday of the great leader comrade Kim Il Sung, 31 March 1982, Pyongyang: Foreign Language Publishing House.

Kim Jong Il (1990b) On Some Problems of the Ideological Foundation of Socialism: Speech delivered to the Senior Officials of the Central Committee of the Workers' Party of Korea, 30 May 1990, Pyongyang: Foreign Language Publishing House.

Kim Jong-won, Kim Ji-soo and Jung Jae-hoon (2016a [2010]) Manual for Guidance Teacher of North Korean Youth Defector, Seoul: Korean Educational Development Institute.

Kim Jung-won, Kim Ji-soo and Jung Jae-hoon (2016b) The Casebook of North Korean Defector Students Mentoring, Seoul: Korean Educational Development Institute.

Kim Jong-won, Kang Gu-sub, Kim Ji-soo, Lee Ji-young, Han Man-gil, Lee Eun-gu, Lee Gwan-hyung, Noh Yu-kyoung, An Kyoung-sik, Kim Sul-hee, Jung Jae-hoon, Gu Seul and Park Ju-young (2015) 6th Annual Report on the North Korea Defector Education Support Center (TR 2015-37), Seoul: Korean Educational Development Institute.

Koreaverband (2015) 'Setnet Theatergruppe zu Besuch in Dresden und Berlin', Koreaverband, 11 November, http:// www.koreaverband.de/blog/2015/11/11/setnet/ accessed 9 September 2016.

Lee Chong-sik (1981) 'Historical Setting, in Bunge, Frederica M. (ed.) North Korea: A Country Study, Washington: American University, Foreign Area Studies, pp: 1-46.

Mackenzie, Natalie (2013) 'A brief exploration of the role of dramatherapy within a multi-modal arts therapy approach to working with children aged between four and fourteen impacted by trauma', Drama Therapy 35(2): 131-9.

Park Sang-young (2016) 'The art activity and the practice of unification of North Korean youth defector's alternative school Setnet', Setnet, http://34school.net/?p=10227, accessed 30 April 2016.

Park Yoon-sook (2007) North Korean Youth Defectors Social Support and Adaptation, Pasu: Korean Studies Information.

Setnet school (2010) 'Introduction of Setnet School: Curriculum', http://34school.net/?page_id=69, accessed 9 September 2016.

Suh Jae-jung (2013) 'Making Sense of North Korea: Jucha as an Institution', in Suh Jae-jung (ed.) Origins of North Korea's Juche: Colonialism, War, and Development, Lanham: Lexington Books, pp.1-32. 